\title{
On the formulation of green open space planning parameters: A parametric tool
}

\author{
Tze Ming Leung, Irina Kukina, Anna Yuryevna Lipovka \\ Institute of Architecture and Design, Siberian Federal University- Siberia. Russia \\ E-mail: jer.jerry@gmail.com, ikukina@inbox.ru, alex.lipovka@gmail.com
}

\begin{abstract}
Greenery can affect spatial characteristics such as relationship between hard and soft surfaces and activities inside open spaces. Among different types of greenery, trees have influences on usage patterns and comfort in open spaces. Trees and hard-soft surfaces in fact form the basis of green open space designs. On the other hand, there has been an increasing number of studies on using parametric tools to design urban environment recently. Despite the success in urban fabric planning by parametric tools, the utilization of these tools to design open spaces with a relatively smaller scale has not been revealed. Even worse, parameters that should be included in a parametric design tool for open space planning are still unknown. Accordingly, the primary objective of this study is to develop a parametric design model for green open space design. By investigating the design characteristics and concepts of different open spaces, parameters for a parametric tool to design green open spaces had been identified. Specifically, hard-soft surfaces in relation to the distribution of trees and entrances to the open space was investigated. This study also aims at developing a methodology for parametric design when designing green open spaces. Results from this study will provide designers with an additional layer of information when designing open spaces.
\end{abstract}

Keywords: greenery, green open spaces, parametric design

\section{Introduction}

Public open spaces are considered one of the basic elements of urban morphology (Palmer \& Thérond, 2012). They are important parts of the urban landscape and should be conceived as "outdoor rooms" within its neighborhood (Rogers \& Urban Task Force, 1999). Due to the increasing awareness about urban sustainability, it is not unusual to have greenery and trees inside public open spaces. These spaces, commonly known as green open spaces (GOS), can provide social, ecological and economic benefits to both individuals and public.

For society, GOS could be regarded as a sort of urban oasis to escape from traffic, noise and pollution of cities (Chiesura, 2004). Places such as urban parks were considered locations for meeting strangers (Thompson, 2002). GOS could even render esthetic enjoyment for individuals (Zhou \& Parves Rana, 2012). Previous studies also showed that GOS could help to promote health and well-being of individuals (Maas et al., 2006). Easy access to GOS such as parks could help to increase the level of walking and physical activities of individuals (Giles-Corti et al., 2005), which would in turn enhance physical health. Positive correlation was suggested between risk of stroke mortality and low exposure to green spaces ( $\mathrm{Hu}$ et al., 2008). GOS also possessed the capability of stress restoration for human beings (Grahn \& Stigsdotter, 2010). Ecologically, GOS could help to regulate urban micro-climate and mitigate urban heat island effects and air pollution (Whitford et al., 2001). Apart from these social 
and ecological benefits, linkage was suggested between property values and the existences of GOS. For example, a study in Spain showed a positive correlation between proximity to green spaces and prices of houses (Morancho, 2003). Because of the multiple benefits of GOS, more efforts should be put on optimizing the design of these spaces.

Regarding the design of urban spaces, there has been an increasing number of studies which explored the feasibility of applying parametric design models in the field of urban design. There are four main advantages for applying parametric urban design models. They are 1) Capacity to quickly generate large generic design; 2) Capacity to add detailing in the early stages of design with little effort; 3) Maintaining the model's 'intelligence' throughout different stages of design; and 4) Facilitating easy testing by changing parameter settings (Steinø \& Obeling, 2013). To this end, extensive efforts have been devoted to developing methodologies and models for parametric urban design. There were studies which focused on identifying the parameters for parametric urban design models (Beirão \& Duarte, 2009). Efforts have also been put on developing algorithm to organize street network in cities (Schneider et al., 2011). Besides, there have been attempts to reveal the possibility of utilizing parametric urban design models for large scale urban planning projects (Koltsova et al., 2011). Although promising results were delivered in previous studies, the parameters for designing GOS were still unknown. Even worse, no attempt has yet been made to investigate the possibility of applying parametric design for individual public open spaces. As a result, it will be of paramount importance to develop a parametric design model for GOS design.

Accordingly, it is of the main interest in this study to develop a parametric model for designing GOS. The current study also aims at identifying the parameters for such parametric model. Another objective of this study is to investigate the methodology for developing a parametric model for GOS design.

\section{Parametric model for GOS design}

Conceptually, the parametric model for GOS design can be expressed by means of a mathematical function:

$Z=F\left(f\left(x_{1}, x_{2}, \cdots, x_{m}\right), g(C)\right)$

In this function, $\mathrm{Z}$ is the final design output of the model. xi's are the parameters and $\mathrm{C}$ is the collection of site conditions / constraints adapted in the parametric model. $\mathrm{f}$ is a function describing the relationship among various parameters. $\mathrm{g}$ is a function describing the relationship of various site conditions / constraints. $\mathrm{F}$ is a function describing the relationship among parameters and site conditions / constraints. $\mathrm{m}$ is the total number of parameters. It can be seen that the function is mainly formed by two parts, namely the site conditions / constraints and the parameters. It would be vital to define these two parts in order to successfully develop a parametric model for GOS design.

\section{Design attributes for GOS design}

Various design attributes could be included in the parametric model. In a study by Lo et al. (2003), extensive literature review has been performed and a total of 23 attributes which would affect GOS design were identified. However, these attributes were mainly related to the internal design of GOS. Attributes related to the immediate surroundings and geometries of the open spaces were not revealed. Besides, the relationship of hard and soft surfaces, as well as the internal connections in the open spaces were not considered. When it comes to the environmental performance of GOS, attributes revealed in the study were mainly related to thermal performance. Acoustic comfort, which should also be an important factor, was not considered. As a result, attributes related to the surroundings, hard-soft surface relationship, internal connections and acoustic comfort of open spaces were appended to these original 23 attributes. Table 1 shows a list of these attributes. 


\section{Model development}

Definition of virtual site and attributes included in the model

Ideally, it would be desirable to develop a model which can adapt to different site conditions. Different geometries, sizes and immediate surrounding conditions should be able to be modified in the model. However, as a pilot study, it has been decided to treat these site conditions as constants in the parametric model. As a result, a virtual site for the model was defined. There were a number of pre-defined conditions which were related to the virtual site. These pre-defined conditions were mostly derived from a brief survey of 19 open spaces

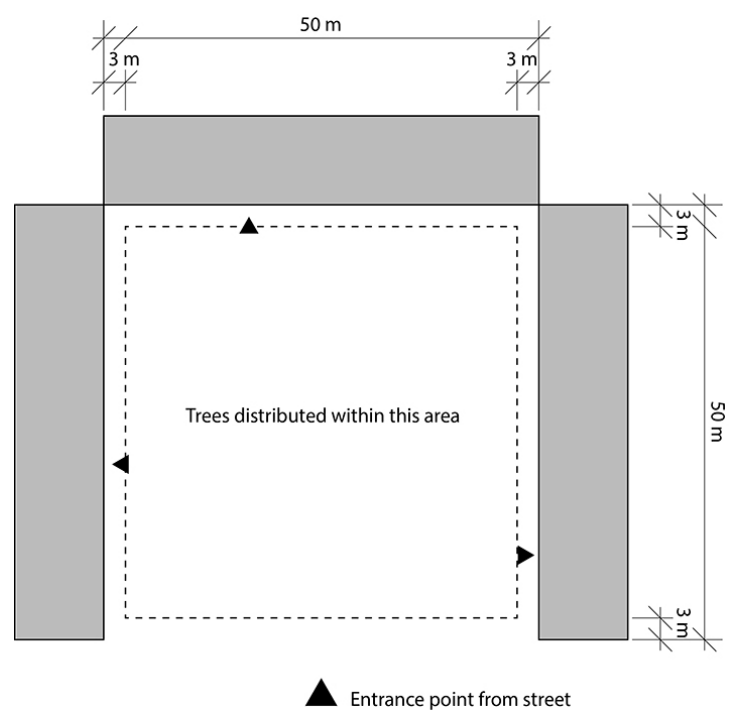

Figure 1. Pre-defined conditions of the virtual site

in Krasnoyarsk, Russia. Firstly, it was assumed that the open space to be designed was in the shape of a square with dimension $50 \mathrm{~m} \times 50 \mathrm{~m}$. Second, the site was enclosed in three sides by buildings, which means that one side of the open space was facing a street. Third, there was only one entrance from each building to the open space. Figure 1 shows the pre-defined conditions set for the virtual site.

Due to the limitation in resources in this study, only five attributes which were considered the most essential and foundamental for GOS design listed in Table 1 were included in the parametric model. They are the number and distribution of trees, the relationship between hard and soft (greenery) surfaces, the entrance point from the street to the open space, the entrances from buildings, and the path connections between the entrances.

As a model for GOS design would be developed, it would be important to first of all consider the trees in the space. There were some constraints when distributing the trees. It was assumed that trees would not be planted on hard surfaces. There would only be trees on soft surfaces. It was also assumed that trees should be placed at least $3 \mathrm{~m}$ from the buildings. This was to prevent trees to be distributed right at the edges of the buildings. Trees in the model were of three different sizes. They were big, middle sized and small trees. Besides, there could be paths (internal connections) among all the entrances. Only the shortest paths among the entrances would be generated as model output. Table 2 summarizes the attributes included in the parametric design model.

\section{Software tool}

A number of criteria were identified when choosing the software tool for developing the parametric models. First of all, the operation of the model should be intuitive. No programming skills should be needed when using the model. To this end, a graphical user interface (GUI) would be preferred. Besides, it would be preferable if no special software is needed when using the model. Moreover, the model should be able to be accessed easily on the internet. This is considered vital as this will mean that designers can access to the model virtually anywhere and anytime. Although there are quite a number of powerful software tools (such as Grasshopper for Rhino 3D and Autodesk Maya MEL) for parametric model development, they all share a common drawback that the model created by these tools cannot be accessed on the internet. As a result, it has been determined that developing an online model would be the best option. PHP, which is a web programming language, and threejs javascript framework were combined to develop the model in this study. 


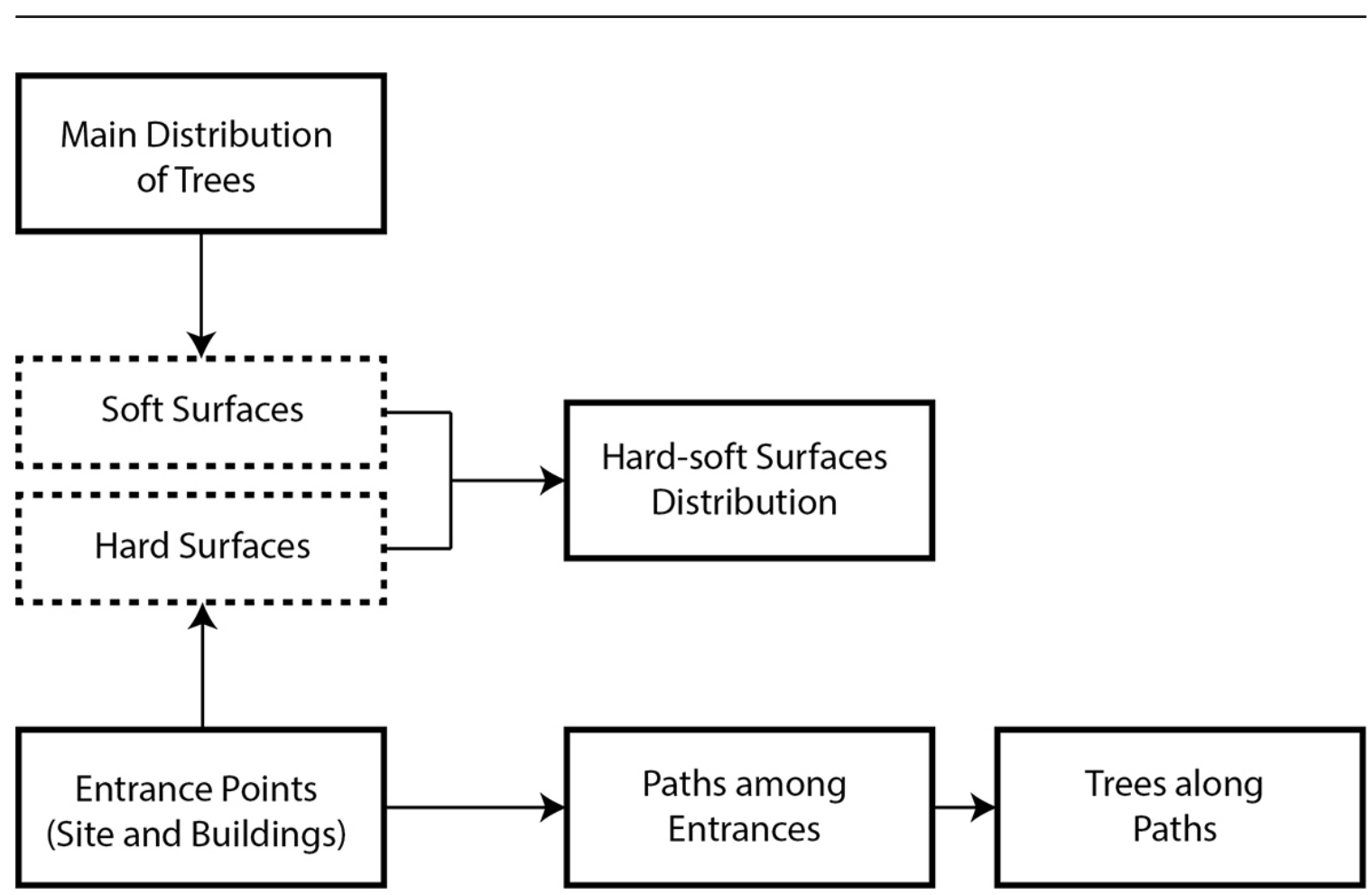

Figure 2. Structure of the parametric model

\section{Parameters and structure of the model}

Although it has been determined that attributes listed in Table 2 should be included in the parametric model, they were not the parameters themselves. As a result, it would be vital to define the parameters based on the attributes included. The values of the parameters should be modifiable when using the model. The change of value of a parameter would affect the results generated by the model. Table 3 shows the parameters the model.

The structure of the model and the flow of generating the final design output are shown in Figure 2 and 3. Distinct points of distance interval $1 \mathrm{~m}$ were defined in the site. There were in total 51 x $51=2601$ points. These points could be defined as hard or soft (green). Positions of trees would also be at some of these points. The first layer of parameters which was defined in the model were the number and distribution of trees. The trees were basically distributed in the open space with a random function. The second layer of information deployed were the green surfaces in the site. There would be green surface within a certain diameter of a tree. The diameters could be modified individually for the three types of trees in the model. On the other hand, the force field of the entrance points would affect the diameter of hard surfaces around the entrances. In reality, the power of the force field could be due to the density of people around the entrance points, connections to important amenities outside the site and so on. For example, the power of the force field could be higher if there was a bus stop at the entrance point of the site. In this study, however, the reason for having a particular power of force field was not considered. It would be the decision of the designers to play with different values of power of force field when exploring design options. It was assumed that the power of the force field followed the inverse-square law. The power of it became weaker when the distance between a particular point in the space and the entrance point was longer. Depending on the power, the force field could override some areas of green surfaces and make it become hard surface. The resultants of force fields of the entrance points and the green surfaces governed by the distribution of trees would be the distribution of hard and soft surfaces in the open space. The paths among the entrances were defined by $\mathrm{A}^{*}$ algorithm, which is an algorithm to search for the shortest path between two points. There could 
be paths among all the entrances, or paths only from the main site entrances to the entrances of

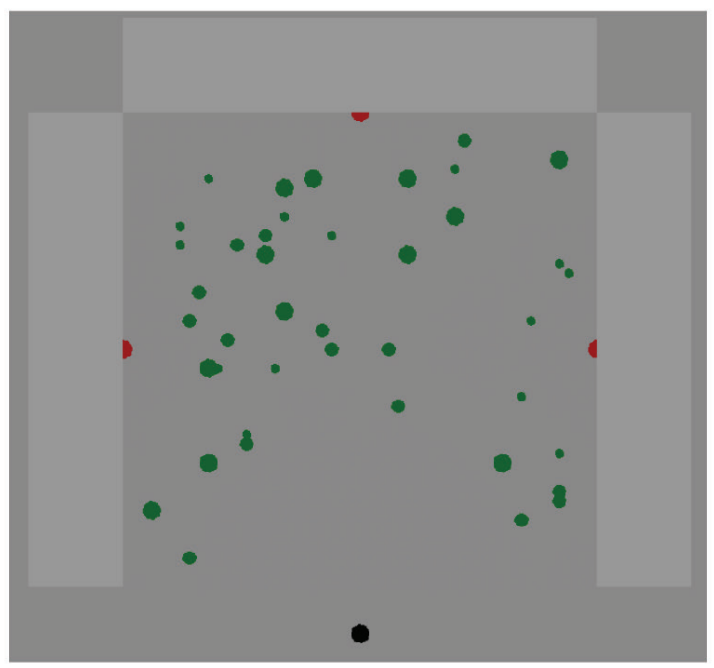

Step 1: Trees and entrances defined

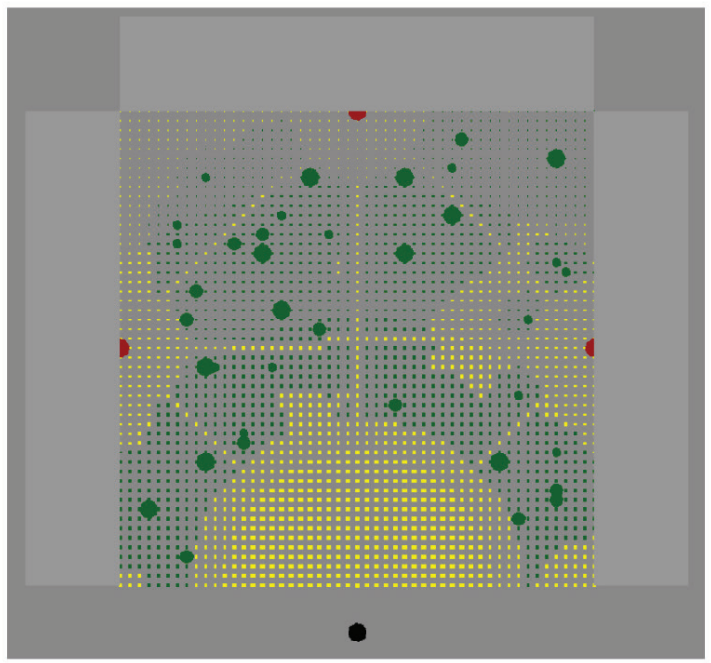

Step 3: Path connctions among entrances buildings. Another additional layer of the parameters is the trees along the paths.

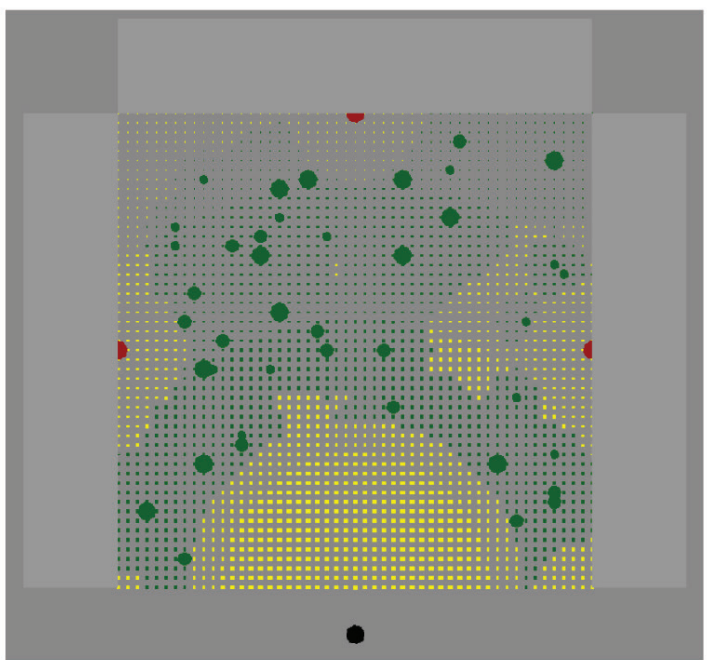

Step 2: Defining hard-soft surfaces according to tree distribution and entrances

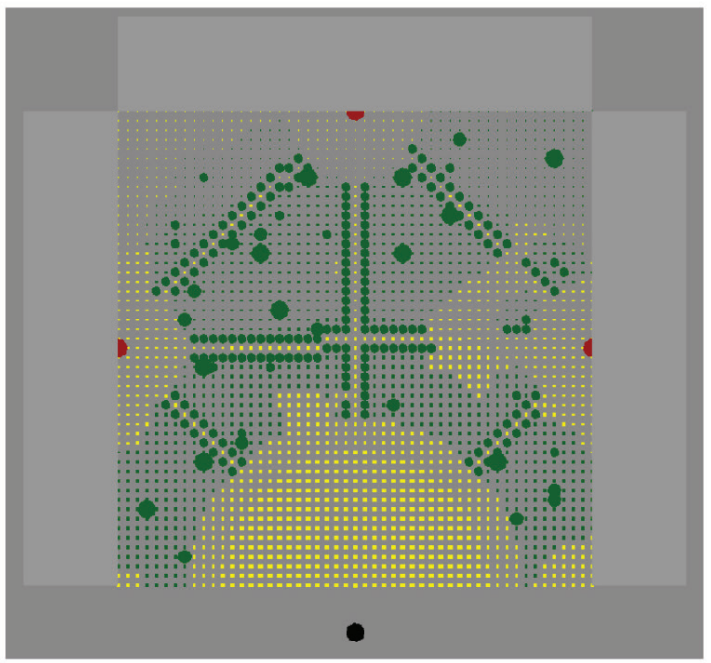

Step 4: Trees along paths

Figure 3. Flow of design output generation

\section{Discussions and conclusion}

In this study, the parameters for a parametric model to design GOS were identified. They included, but not limited to, number and distribution of trees, diameter of soft surfaces surrounding trees, positions and force fields of entrance points, paths connecting the entrance points, as well as trees along the paths. Although the number of parameters included were limited in this study, they were considered the most basic and essential parameters for a parametric model for GOS design. Besides, a structure of the parametric model was proposed. The distribution of trees would firstly be defined. With both tree distribution and the entrance points, the relationship between hard and soft surfaces would be defined. Meanwhile, the path connecting the entrance points would be defined according to the positions of the entrance points. Lastly, trees along these paths would be generated.

Although the feasibility of utilizing parametric model for GOS design was demonstrated in 
this study, it is essential to note that the design generated is not meant to be the final design solution. Instead, the output of the model is to facilitate the generation of different possibilities and alternatives in the early design stage. Usually, designers will only consider one element of design (trees or internal paths for examples) at a time in the early design stage. The model can help to unfold different elements at the same time at this stage. This can probably help designers to have better understanding of different design options when they start the design process.

It should also be noted that the approach in this study has to be further explored. As per the current model, the conditions and constraints of the site could not be modified. This could limit the application of the model in real sites. Consequently, it would be desirable to make the model more flexible in a way that the site conditions and constraints can be input. It is recommended that conditions such as size and geometry of the site could be modifiable within the GUI in future studies. Another weakness of the current model is that trees were distributed with a random function. A more solid mathematical function could be defined for tree distribution in future studies. For instance, tree distribution could be related to the building enclosing the open space, or the shadow projected by the buildings. Nonetheless, the model in this study should have laid a solid foundation for future development of parametric GOS design.

Table 1. Attributes affecting GOS design (modified from Lo et al. (2003))

\begin{tabular}{|c|c|}
\hline Category & Attributes \\
\hline \multirow[t]{5}{*}{ Site } & Location \\
\hline & Size \\
\hline & Geometry \\
\hline & Entrances \\
\hline & Buildings surrounding the site \\
\hline Greenery and Planting & Trees \\
\hline & Hard-soft surface relationship \\
\hline \multirow[t]{9}{*}{ Facilities } & Amount of seating \\
\hline & Seating materials \\
\hline & Orientation of seating \\
\hline & Sitting height \\
\hline & Integral sitting \\
\hline & Sculpture \\
\hline & Fountain \\
\hline & Paving \\
\hline & Internal connections \\
\hline \multirow[t]{3}{*}{ Amenities } & Food \\
\hline & Programs \\
\hline & Toilets \\
\hline \multirow[t]{5}{*}{ Environmental performance } & Solar access \\
\hline & Temperature \\
\hline & Wind \\
\hline & Sound level \\
\hline & G1are \\
\hline \multirow[t]{5}{*}{ Others } & Visibility \\
\hline & Accessibility \\
\hline & Visual complexity \\
\hline & Safety \\
\hline & Management \\
\hline
\end{tabular}


Table 2. Attributes included in the parametric design model

\begin{tabular}{ll}
\hline Attributes & Description \\
\hline Surfaces & - Hard or Soft (green) surfaces \\
Trees & - Only on soft surfaces \\
& - 3 Types: Big, Middle sized, Small \\
Site Entrance & - Entrance facing the street \\
Building Entrances & - One from each building to the green space \\
Internal Connections & - Street entrance to building entrances \\
& - Among building entrances \\
& - Shortest path between two entrance points \\
\hline
\end{tabular}

Table 3. Parameters of the model

\begin{tabular}{ll}
\hline Parameters & Description \\
\hline Number of tree & - Values: 10 to 300 \\
Soft surfaces surrounding trees & - Distance (radius) from a tree that would be of soft surface \\
& - Individual values for each of the three types of trees \\
- Values: $1 \mathrm{~m}$ to $10 \mathrm{~m}$
\end{tabular}




\section{References}

Beirão, J. N. and Duarte, J. P. (2009) 'Urban design with patterns and shape rules', In E. Stolk and M. te Brömmelstroet (Eds.) Model Town: Using Urban Simulation in New Town Planning (SUN, Amsterdam).

Chiesura, A. (2004) 'The role of urban parks for the sustainable city', Landscape and Urban Planning 68(1), 129-138. https://doi. org/10.1016/j.landurbplan.2003.08.003

Giles-Corti, B., Broomhall, M. H., Knuiman, M., Collins, C., Douglas, K., Ng, K., Lange, A. and Donovan, R. J. (2005) 'Increasing walking: How important is distance to, attractiveness, and size of public open space?', American Journal of Preventive Medicine 28(2), 169-176. https://doi. org/10.1016/j.amepre.2004.10.018

Grahn, P. and Stigsdotter, U. K. (2010) 'The relation between perceived sensory dimensions of urban green space and stress restoration', Landscape and Urban Planning 94(3), 264-275. https://doi.org/10.1016/j. landurbplan.2009.10.012

$\mathrm{Hu}$, Z., Liebens, J. and Rao, K. R. (2008) 'Linking stroke mortality with air pollution, income, and greenness in northwest Florida: an ecological geographical study', International Journal of Health Geographics $7(20)$.

Koltsova, A., Schmitt, G., Schumacher, P., Sudo, T., Narang, S. and Chen, L. (2011) 'A Case Study of Script-Based Techniques in Urban Planning', In Design Computing and Cognition '10 (Springer Netherlands, Dordrecht) 681-700. https:// doi.org/10.1007/978-94-007-0510-4_36

Lo, S. M., Yiu, C. Y. and Lo, A. (2003) 'An analysis of attributes affecting urban open space design and their environmental implications', Management of Environmental Quality: An International Journal 14(5), 604-14. https://doi. org/10.1108/14777830310495759

Maas, J., Verheij, R. A., Groenewegen, P. P., Vries, S. de and Spreeuwenberg, P. (2006) 'Green space, urbanity, and health: how strong is the relation?', Journal of Epidemiology and Community Health 60(7), 587-92.
Morancho, A. B. (2003) 'A hedonic valuation of urban green areas', Landscape and Urban Planning 66(1), 35-41. https://doi. org/10.1016/S0169-2046(03)00093-8

Palmer, R. and Thérond, D. (2012) Public Space and Landscape: The Human Scale (Council of Europe Directorate of Culture and Cultural and Natural Heritage Cultural Heritage, Landscape and Spatial Planning Division, Strasbourg).

Rogers, R. and Urban Task Force. (1999) Towards an Urban Renaissance: Final Report of the Urban Task Force Chaired by Lord Rogers of Riverside (Department of the Environment, Transport and the Regions, London).

Schneider, C., Koltsova, A. and Schmitt, G. (2011) 'Components for parametric urban design in Grasshopper: From street network to building geometry', In Proceedings of the 2011 Symposium on Simulation for Architecture and Urban Design (Boston).

Steinø, N. and Obeling, E. (2013) 'Parametrics in Urban Design: A Bridge to Cross the Gap Between Urban Designer and Urban Dweller?', In Proceedings of Hybrid City II (Athens).

Thompson, C. W. (2002) 'Urban open space in the 21st century', Landscape and Urban Planning 60(2), 59-72. https://doi. org/10.1016/S0169-2046(02)00059-2

Whitford, V., Ennos, A. R. and Handley, J. F. (2001) 'City form and natural processindicators for the ecological performance of urban areas and their application to Merseyside, UK', Landscape and Urban Planning 57(2), 91-103. https://doi. org/10.1016/S0169-2046(01)00192-X

Zhou, X. and Parves Rana, M. (2012) 'Social benefits of urban green space: A conceptual framework of valuation and accessibility measurements', Management of Environmental Quality: An International Journal 23(2), 173-89. https://doi. org/10.1108/14777831211204921 